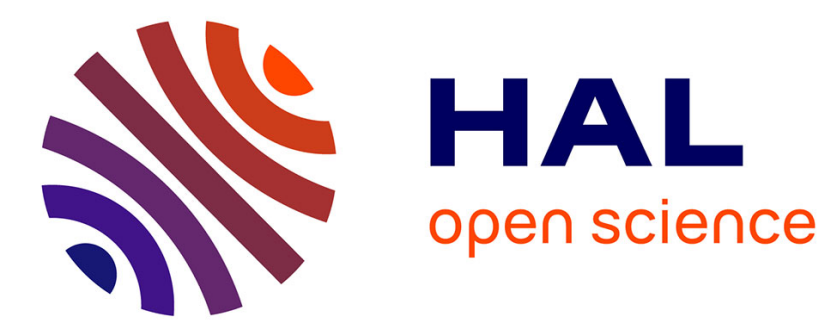

\title{
Integrating pharmacogenetics and therapeutic drug monitoring: optimal dosing of imatinib as a case-example
}

Alain Li-Wan-Po, Peter Farndon, Charles Craddock, Michael Griffiths

\section{To cite this version:}

Alain Li-Wan-Po, Peter Farndon, Charles Craddock, Michael Griffiths. Integrating pharmacogenetics and therapeutic drug monitoring: optimal dosing of imatinib as a case-example. European Journal of Clinical Pharmacology, 2010, 66 (4), pp.369-374. 10.1007/s00228-009-0779-4 . hal-00560681

\section{HAL Id: hal-00560681 \\ https://hal.science/hal-00560681}

Submitted on 29 Jan 2011

HAL is a multi-disciplinary open access archive for the deposit and dissemination of scientific research documents, whether they are published or not. The documents may come from teaching and research institutions in France or abroad, or from public or private research centers.
L'archive ouverte pluridisciplinaire HAL, est destinée au dépôt et à la diffusion de documents scientifiques de niveau recherche, publiés ou non, émanant des établissements d'enseignement et de recherche français ou étrangers, des laboratoires publics ou privés. 


\title{
Integrating pharmacogenetics and therapeutic drug monitoring: optimal dosing of imatinib as a case-example
}

\author{
Alain Li-Wan-Po • Peter Farndon • Charles Craddock • \\ Michael Griffiths
}

Received: 23 October 2009 / Accepted: 17 December 2009/Published online: 29 January 2010

(C) Springer-Verlag 2010

\begin{abstract}
Purpose To illustrate the interface of pharmacogenetics and therapeutic drug monitoring and to estimate target blood level for imatinib in the treatment of chronic myelogenous leukemia Methods A literature review to provide the evidence and necessary data to support the case for the interface, and quantitative analysis of the data to estimate the target blood level for imatinib using receiver operating curve (ROC; signal detection theory) analysis.

Results and discussion One study estimated the optimum target level of imatinib in chronic myelogenous leukaemia as $1002 \mathrm{ng} / \mathrm{mL}(1.70 \mu \mathrm{M})$ through ROC analysis. Using individual-patient level data reported in another study and the same methodology, we estimated the target level as $0.95 \mu \mathrm{M}$. This is consistent with the results of other observational studies where dose-response was not the primary research objective. The available evidence suggests
\end{abstract}

\footnotetext{
A. Li-Wan-Po $(\bowtie) \cdot$ P. Farndon

National Genetics Education and Development Centre,

Morris House, c/o Birmingham Women's Hospital,

Edgbaston,

Birmingham B15 2TG, UK

e-mail: a.liwanpo@talk21.com

P. Farndon

e-mail: p.a.farndon@bham.ac.uk

C. Craddock

Department of Haematology, Queen Elizabeth Hospital,

Birmingham, UK

e-mail: charles.craddock@uhb.nhs.uk

M. Griffiths

West Midlands Regional Genetics Laboratory, Birmingham Women's NHS Foundation Trust,

Edgbaston,

Birmingham, UK

e-mail: Mike.griffiths@bwhct.nhs.uk
}

considerable inter-individual variability in dose-blood level response. In addition to the pharmacogenetics of metabolic enzymes and transporters, genetic mutations in genes participating in the signalling pathways may also account for the wide inter-individual variability in dose-blood level and dose-clinical response relationships.

Conclusion A single-dose regimen for all pharmacogenetically eligible patients is not the optimum strategy for prescribing imatinib to patients with chronic myelogenous leukaemia. We suggest that therapeutic drug monitoring aimed at ensuring a trough target level of $1 \mu \mathrm{M}$ would reduce the incidence of pseudo-resistance and hence personalize treatment and optimise response to imatinib. Persistent resistance can then be probed further for other causes.

Keywords Chronic myeloid leukaemia · Imatinib resistance $\cdot$ Personalized medicine .

Therapeutic drug monitoring

\section{Introduction}

Imatinib is, even within the context of targeted therapies, a molecular therapeutic star [1,2]. Its major impact in the management of chronic myelogenous leukaemia (CML) and gastro-intestinal stromal tumours (GIST), is widely acknowledged and has arguably led to the growing and resurgent interest in translational research in medicine. Yet, despite its selectivity of action and relatively benign harmbenefit profile, imatinib does not cure. Using Paul Ehrlich's weaponry metaphor, the magic bullet stuns but does not cure, leaving behind resistant cancer cells to challenge the host on another occasion. The precise mechanisms for imatinib resistance and treatment failure are still unclear, but residual cancer stem cells and the emergence of new 
mutations made easier from the genomic instability characteristic of cancer cells [3] are plausible explanations for at least some of the cases.

An increasing body of evidence suggests that for a substantial number of cases, resistance may be apparent (pseudo-resistance) rather than true imatinib resistance, in that dose escalation leads to drug response [4-6]. The reasons why the standard dose of imatinib fails to achieve the expected response in some patients include interindividual variability in the differential expression of the influx (hOCT1) and efflux (MDR1) transporters [7] and variable bioavailability $[8,9]$. In an analysis of the clinical significance of imatinib pharmacokinetics [10], using data from the IRIS study [11, 12], subjects given $400 \mathrm{mg}$ daily had trough levels ranging from 153 to $3910 \mathrm{ng} / \mathrm{mL}$. It was also clear from this analysis that an adequate plasma concentration is important for a good drug response. Fixed dosing is therefore not the best approach to ensuring a good response. If blood level is important, however, the question then arises as to what the target level ought to be for therapeutic drug monitoring (TDM). The aim of our study was, therefore, to critically appraise the available evidence with a view to estimating this optimal blood level. In the Discussion section, we then suggest how TDM, with this target blood level, could interface with pharmacogenetic data to optimise therapy.

\section{Method}

We undertook a search for lead papers on dose-response with a keyword search on dose, monitoring, dose regimens and therapeutic monitoring, each with the qualifiers imatinib. We then retrieved the relevant papers based on the content of the abstracts and did historical searches through the references lists of those papers. We abstracted and subjected relevant data to statistical analysis, including receiver operating characteristic (ROC, signal detection theory) curve analysis [13].

\section{Results and discussion}

In a recent report, Picard et al. [8] studied the association between imatinib trough blood level and treatment response in CML patients who were given 400 or $600 \mathrm{mg}$ imatinib daily, depending on whether they were in the chronic phase or accelerated phase of the disease. The treatment response was major molecular response, defined as a reduction in the BCR-ABL transcript level of at least 3 logs after 12 months of therapy from the standardised baseline. Despite the variable dosing and staging of the disease, using ROC curve analysis, the authors estimated, using major molec- ular response as outcome, that with the optimal sensitivity and specificity trade-off, the optimal threshold imatinib steady-state trough plasma level was $1002 \mathrm{ng} / \mathrm{mL}$ (1.70 $\mu \mathrm{M}$; molecular weight 589.7).

In a second report, Singh et al. [9] studied 40 chronic phase CML patients treated with $400 \mathrm{mg}$ imatinib daily and reported that mean steady-state trough plasma was significantly lower in non-responders than in responders ( $0.70 \mathrm{vs.}$ $2.34 \mu \mathrm{M} ; p=0.002)$. These researchers defined responders as those who achieved a complete haematological response within 3 months of initiating treatment or those who demonstrated a major cytogenetic response within 6 months of treatment initiation, both responses following the administration of imatinib mesylate at $400 \mathrm{mg} /$ day. Although they did not mathematically estimate the optimum plasma level for a response, they did report the individual levels for both responders and non-responders. Using the approach adopted by Picard et al. [8], we calculated the ROC curve for the data reported by Singh et al. [9] (Fig. 1) and obtained an area under the ROC curve of 0.78 , which is the same as that reported by Picard et al. [8]. We also estimated the target trough plasma level of imatinib, again using Singh et al.'s data [9] under conditions of a trade-off of sensitivity versus specificity (Fig. 2) and obtained a value of $0.95 \mu \mathrm{M}$; , which is lower than that reported by Picard et al. [8]. Using the variance estimates of the blood levels, observed by Singh et al. [9] and Picard et al. [8] in their responder groups, we have calculated the $95 \%$ confidence intervals for optimal trough threshold to be 1.33-2.07 $\mu \mathrm{M}$ and $0.88-1.02 \mu \mathrm{M}$ respectively. When we used the optimal cut-off mean blood level of $0.95 \mu \mathrm{M}$, obtained using Singh et al.'s data, the sensitivity was $75 \%$, the specificity $85 \%$, the positive predictive value $83 \%$, the negative predictive value $77 \%$ and the percentage of subjects correctly classified $90 \%$.

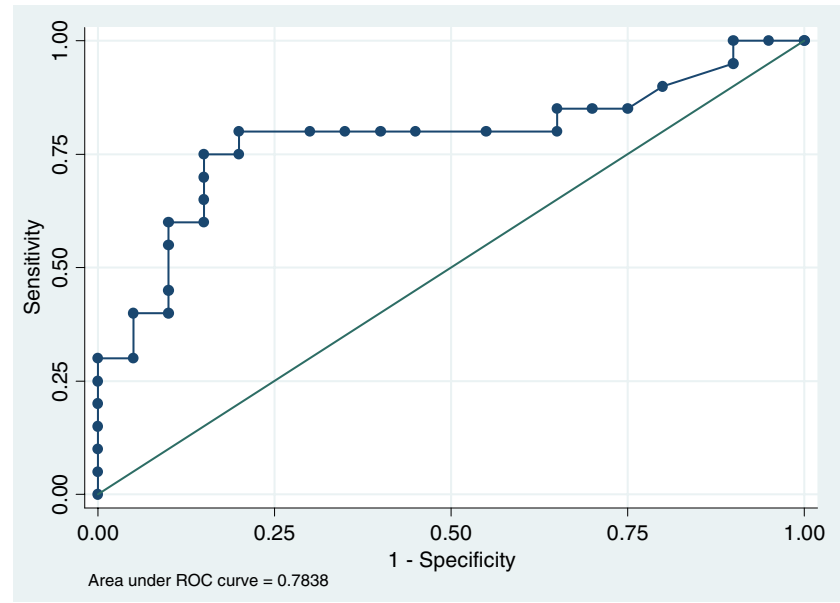

Fig. 1 Calculation of the receiver operating characteristic (ROC) curve using the data of Singh et al. [9] 


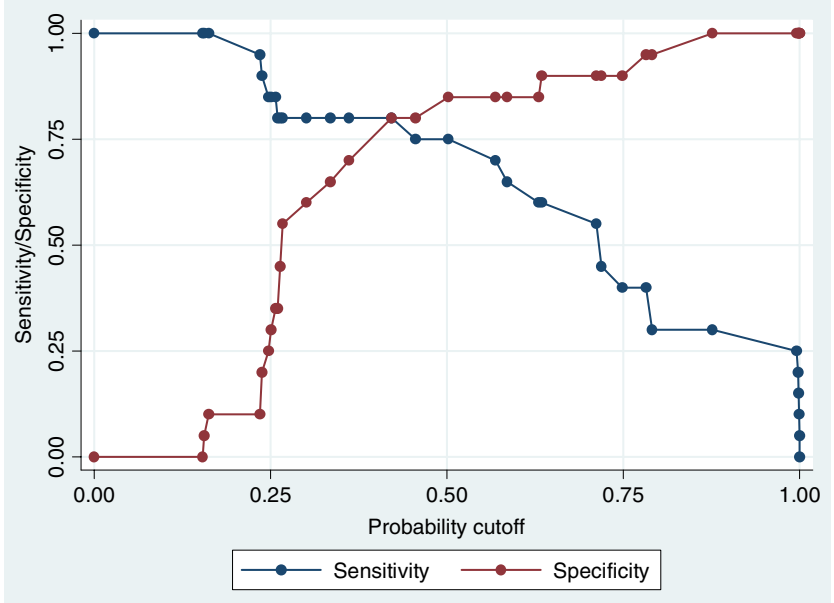

Fig. 2 Sensitivity and specificity trade-offs for estimating target trough level of imatinib based on Singh et al.'s data [9]

Dose escalation without TDM

If the target imatinib level is known for imatinib pseudoresistant CML, how effective would a simple dose adjustment be without measurement of the trough plasma level (i.e. without TDM)? In addition to an earlier preliminary report [4], two very recent reports address this issue [5, 6]. Kantarjian et al. [5], in their retrospective analysis of 106 patients enrolled in the IRIS trial $[11,12]$, reported that dose escalation from 400 to 600 or $800 \mathrm{mg}$ daily, according to the predefined trial protocol or as recommended by European LeukemiaNet guidelines [14], led to about $40 \%$ of patients obtaining a cytogenetic response. Jabbour et al. assessed the longterm efficacy of imatinib dose escalation (400 to $800 \mathrm{mg}$, or 300 to $600 \mathrm{mg}$ ) in patients with chronic phase CML who had demonstrated a poor response or relapse on standard-dose imatinib [6]. After a median follow-up of 61 months from dose escalation, more than two-thirds of the patients were still alive: $40 \%$ achieved complete cytogenetic response, $88 \%$ of whom sustained their response beyond 2 years [6].

Those two studies [5, 6], both of which were led by the Anderson Cancer Centre in Texas, were retrospective analyses of patients enrolled in other studies [4, 15-17], including those randomised to $400 \mathrm{mg}$ imatinib in the IRIS randomised controlled study [11]. To test the value of dose escalation further, Baccarani et al. [18] compared response to 400 or $800 \mathrm{mg}$ daily as the first-line treatment of patients with Philadelphia-positive chronic myeloid leukaemia, defined as high-risk on the basis of the Sokal prognostic classification, which focuses on percentage blasts, spleen size, platelet count and age. Their randomised controlled study surprisingly showed no significant difference between those two dosage regimens (64 vs. $58 \%$ with complete cytogenetic response in the $800 \mathrm{mg}$ group vs. the $400 \mathrm{mg}$ group). This led the authors to guard against extensive use of the higher dose [18].

Value of TDM

Although the dose-plasma steady-state concentration relationship shows some dose-response linearity, at the higher dose levels, daily single-dose administration suggests some saturation (Fig. 3). Moreover, there is considerable interpatient variability, as shown by the wide inter-subject variability in steady-state plasma level reached in patients given the same dose (Fig. 3). Variability increases with increasing dose so that not all patients reach the target level, even at a dose of $600 \mathrm{mg}$ daily. Figure 3 shows that at the $1200 \mathrm{mg}$ daily dose, the $95 \%$ confidence interval extended from $<3 \mu \mathrm{M}$ to $>9 \mu \mathrm{M}$. Therefore, patients given a higher dose may not achieve a given target concentration. Using Peng et al.'s data and assuming normality, on average, $26 \%$ of patients given a $400 \mathrm{mg}$ dose would not achieve Picard et al.'s target trough level of $1002 \mathrm{ng} / \mathrm{mL}(1.70 \mu \mathrm{M})$ compared to less than $0.2 \%$ of those given $800 \mathrm{mg}$; using Singh et al.'s threshold of $0.95 \mu \mathrm{M}$, the corresponding values are 2.6 and $0.0001 \%$. Therapeutic dose monitoring would therefore be useful for dose adjustment in order to minimise the number of cases of suboptimal dosing and to obviate the use of the higher dose for all patients. Moreover, the TDM data collected over time would also provide a valuable resource for estimating, through retrospective analyses, the optimum trough blood level for different subgroups of patients, such as those in the blast phase of the disease. These levels can then be efficiently validated through well-designed randomised controlled trials.

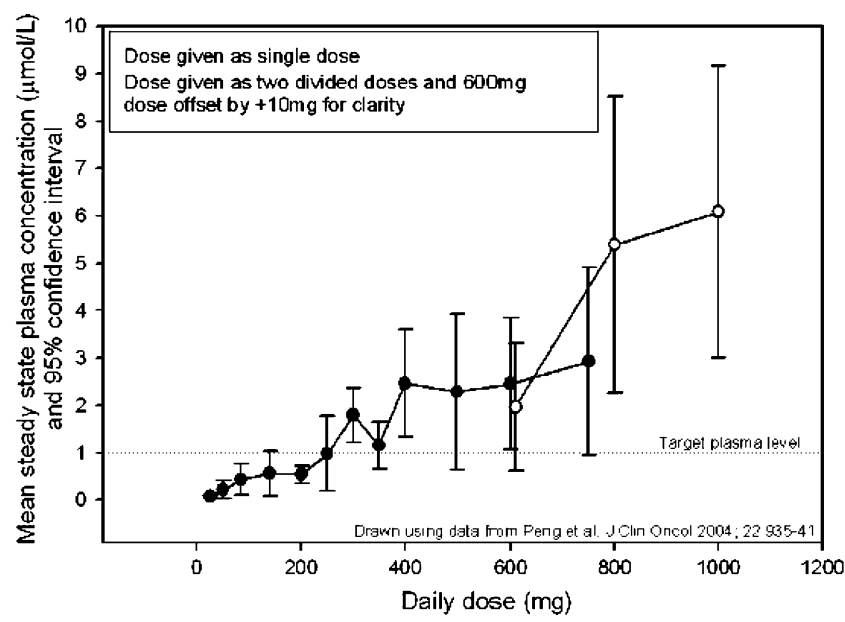

Fig. 3 Imatinib oral dose and steady-state trough plasma concentration relationship (closed circles: once-daily dosing; open circles: twice-daily dosing) 
Interfacing pharmacogenetics and TDM

A recent UK House of Lords report [19] warned against genetic exceptionalism, which in the present context can be roughly defined as giving 'privilege to DNA-based information over other types of information', namely other clinical and background data 'that may be equally or more predictive' in the management of individual patients. The case presented here illustrates well the synergy to be derived from integrating pharmacogenetic information, namely the presence of the $B C R-A B L 1$ gene, with TDM of the targeted agent. In CML confirmed by the presence of the appropriate genetic variant (cytogenetically as the Philadelphia chromosome or molecularly as the $B R C$ $A B L 1$ gene, or the encoded constitutively activated oncoprotein), imatinib is now the first-line treatment in settings where the drug is affordable. This pharmacogenetictargeting benefits from conventional TDM, which ensures that the target level is reached without uncritical doseescalation, thereby reducing the risk of a severe unwanted adverse effect [20].

Although the dose-toxicity response for imatinib is not unequivocally positive, a number of published clinical reports suggest that high doses are less well tolerated. For example, in the LeukemiaNet study, at 12 months, the proportion of subjects discontinuing treatment because of adverse events were approximately twofold higher in those receiving $800 \mathrm{mg}$ daily than in those on $400 \mathrm{mg}$ daily $(9 /$ 108 vs. 5/108) [18]. In a recent study of dose escalation after the therapeutic failure of standard-dose imatinib, Jabbour et al. reported that dose reduction was necessary to resolve toxicity problems during long-term follow-up (median 61 months, range 7-89 months), most notably myelosuppression, which affected 13 of the 84 patients, and fluid retention, which affected seven patients. Moreover, in common with many of the newer targeted agents, imatinib is an expensive drug, costing an estimated US $\$ 42,000$ per year at standard doses [21]. Optimum dosing and pharmaco-economic optimisation help in avoiding unnecessary waste of scarce resources [22]. In some patients, disease control, even with the achievement of the target blood level, may still not be achieved. Current evidence suggests that this may be due to additional mutations conferring resistance [23], and alternative strategies are then necessary, including the use of other targeted agents and combination therapy [24, 25]. However, neither nilotinib nor dasatinib appears to provide durable responses after failure of imatinib [26]. Multikinase inhibitors, such as bosotunib, also appear to have only limited effects in such patients [27]. Allogenic stem-cell transplantation has also been suggested for eligible patients [28].

While the targeting of BCR-ABL1 with imatinib is the first, pharmacogenetically guided, logical step in treating
CML patients, the use of imatinib is complicated by other aspects of the pharmacogenetics of this drug. Imatinib is metabolised by several of the cytochrome P450 enzymes (CYP450). Of these, CYP3A4 and CYP3A5 appear to be the most important, although CYP1A2, CYP2D6, CYP2C9 and CYP2C19 may also participate [29, 30]. However, to date, none of the studied CYP450 metabolic enzyme genotypes have shown sufficiently strong predictive power to be useful for imatinib dose-blood level prediction in clinical practice [30] when assessed using methodology we have described elsewhere for other types of genetic testing for both prognostic purposes [31] and critical evaluation of the impact of new variants [32]. This may be due to the complex interactions in the expression of the CYP450 enzymes [33-35], including epigenetic effects, the participation of microRNAs [36] and their polymorphisms [37] and the interplay between transporters and metabolic enzymes, which has yet to be fully unravelled [38].

Polymorphism of genes coding for transporters are wellknown causes of drug resistance in cancer chemotherapy. The $A B C B 1$ [39] and $A B C B 2$ [40] genotypes have been associated with imatinib clearance, although the strengths of association uncovered are, similar to those of the metabolic enzymes, relatively weak and unlikely to be clinically useful for predicting efficacy.

In addition to the gene products which might affect imatinib pharmacokinetics, a number of genes, possibly those involved in the signalling pathways, have also been evaluated with promising results [41, 42]. However, again the analyses had insufficient predictive power for routine clinical use.

\section{Other considerations}

Given the potential impact on the imatinib's clinical effects, several studies have considered the effect of potential drug interactions on its blood level. Thus, when the potent inducer of CYP3A4, rifampicin, was given concomitantly with imatinib, the area under the concentration-time curve $\left.\left[\mathrm{AUC}_{(0-24} \mathrm{h}\right)\right]$ of the targeted agent decreased by $68 \%$ (95\% confidence interval $64-70 \%$ ). This magnitude of change is large enough to be most likely clinically significant, and such interactions should therefore be guarded against [43]. Imatinib, itself an inhibitor of CYP3A4, has been shown to significantly inhibit the metabolism of substrates of this enzyme [44]. Given the increased likelihood of combination therapy in cancer patients, constant vigilance is therefore necessary. As patients may inadvertently take non-prescribed herbal and over-the-counter medicines, or indeed dietary components, which may interact, TDM may be the only means of ensuring optimum therapy with critical drugs, such as 
imatinib. Therapeutic drug monitoring should also help in identifying the non-compliant patient or other unknown factors affecting the achievement of a target blood level despite adequate dosing.

\section{Conclusion}

Pharmacogenetic targeting of imatinib in patients with CML is done through the identification of the appropriate genetic variant. Our review and analysis shows that for those patients, a target threshold trough blood level of at least $1 \mu \mathrm{M}$ and perhaps as high as $1.7 \mu \mathrm{M}$ would be optimum initially. In the era of personalized medicine, this is best achieved through TDM given the large inter-patient variability in the pharmacokinetics of imatinib and the inadequate predictive power of genetic testing and profiling investigated to date, other than the presence of the $B C R-A B L 1$ oncogene. Therapeutic drug monitoring should ensure that a highly effective drug is used even more effectively to minimise the incidence of pseudo-resistance.

\section{References}

1. Schwartz R (2002) A molecular star in the wars against cancer. N Engl J Med 347(7):462-463

2. Demetri GDvMM, Blanke CD et al (2002) Efficacy and safety of imatinib mesylate in advanced gastrointestinal stromal tumors. A molecular star in the wars against cancer. N Engl J Med 347:472480

3. Wardelmann E, Thomas N, Merkelbach-Bruse S, Pauls K, Speidel $\mathrm{N}$, Buttner $\mathrm{R}$ et al (2005) Acquired resistance to imatinib in gastrointestinal stromal tumours caused by multiple KIT mutations. Lancet Oncol 6(4):249-251

4. Kantarjian HM, Talpaz M, O'Brien S, Giles F, Garcia-Manero G, Faderl S et al (2003) Dose escalation of imatinib mesylate can overcome resistance to standard-dose therapy in patients with chronic myelogenous leukemia. Blood 101(2):473-475

5. Kantarjian HM, Larson RA, Guilhot F, O'Brien SG, Mone M, Rudoltz M et al (2009) Efficacy of imatinib dose escalation in patients with chronic myeloid leukemia in chronic phase. Cancer 115(3):551-560

6. Jabbour E, Kantarjian HM, Jones D, Shan J, O'Brien S, Reddy N et al (2009) Imatinib mesylate dose escalation is associated with durable responses in patients with chronic myeloid leukemia after cytogenetic failure on standard-dose imatinib therapy. Blood 113 (10):2154-2160

7. Thomas J, Wang L, Clark RE, Pirmohamed M (2004) Active transport of imatinib into and out of cells: implications for drug resistance. Blood 104(12):3739-3745

8. Picard S, Titier K, Etienne G, Teilhet E, Ducint D, Bernard MA et al (2007) Trough imatinib plasma levels are associated with both cytogenetic and molecular responses to standard-dose imatinib in chronic myeloid leukemia. Blood 109(8):3496-3499

9. Singh N, Kumar L, Meena R, Velpandian T (2009) Drug monitoring of imatinib levels in patients undergoing therapy for chronic myeloid leukaemia: comparing plasma levels of res- ponders and non-responders. Eur J Clin Pharmacol 65(6):545549

10. Larson RA, Druker BJ, Guilhot F, O'Brien SG, Riviere GJ, Krahnke $T$ et al (2008) Imatinib pharmacokinetics and its correlation with response and safety in chronic-phase chronic myeloid leukemia: a subanalysis of the IRIS study. Blood 111 (8):4022-4028

11. O'Brien SG, Guilhot F, Larson RA, Gathmann I, Baccarani M, Cervantes $F$ et al (2003) Imatinib compared with interferon and low-dose cytarabine for newly diagnosed chronic-phase chronic myeloid leukemia. N Engl J Med 348(11):994-1004

12. Druker BJ, Guilhot F, O'Brien SG, Gathmann I, Kantarjian H, Gattermann N et al (2006) Five-year follow-up of patients receiving imatinib for chronic myeloid leukemia. N Engl J Med 355(23):2408-2417

13. Green DM, Swets JA (1966) Signal detection theory and psychophysics. Peninsula Publ, Los Altos

14. Baccarani M, Saglio G, Goldman J, Hochhaus A, Simonsson B, Appelbaum $\mathrm{F}$ et al (2006) Evolving concepts in the management of chronic myeloid leukemia: recommendations from an expert panel on behalf of the European LeukemiaNet. Blood 108 (6): 1809-1820

15. Joensuu H, Roberts PJ, Sarlomo-Rikala M, Andersson LC, Tervahartiala P, Tuveson D et al (2001) Effect of the tyrosine kinase inhibitor STI571 in a patient with a metastatic gastrointestinal stromal tumor. N Engl J Med 344(14):1052-1056

16. Kantarjian H, Sawyers C, Hochhaus A, Guilhot F, Schiffer C, Gambacorti-Passerini C et al (2002) Hematologic and cytogenetic responses to imatinib mesylate in chronic myelogenous leukemia. N Engl J Med 346(9):645-652

17. Kantarjian HM, Talpaz M, O'Brien S, Smith TL, Giles FJ, Faderl $S$ et al (2002) Imatinib mesylate for Philadelphia chromosomepositive, chronic-phase myeloid leukemia after failure of interferon-alpha: follow-up results. Clin Cancer Res 8(7):21772187

18. Baccarani M, Rosti G, Castagnetti F, Haznedaroglu I, Porkka K, Abruzzese E et al (2009) Comparison of imatinib $400 \mathrm{mg}$ and $800 \mathrm{mg}$ daily in the front-line treatment of high-risk, Philadelphiapositive chronic myeloid leukemia: a European LeukemiaNet study. Blood 113(19):4497-4504

19. Science and Technology Committee (2009) Genomic medicine, vol 1. House of Lords, London

20. Mauro MJ (2009) Tailoring tyrosine kinase inhibitor therapy in chronic myeloid leukemia. Cancer Control 16(2):108-121

21. Pollack A (2009) As pills treat cancer, insurance lags behind. New York Times 2009, April 15th:A1

22. Steinbrook R (2008) Saying no isn't NICE - the travails of Britain's National Institute for Health and Clinical Excellence. N Engl J Med 359(19):1977-1981

23. Kim DH, Sriharsha L, Xu W, Kamel-Reid S, Liu X, Siminovitch $\mathrm{K}$ et al (2009) Clinical relevance of a pharmacogenetic approach using multiple candidate genes to predict response and resistance to imatinib therapy in chronic myeloid leukemia. Clin Cancer Res 15(14):4750-4758

24. Quintas-Cardama A, Kantarjian HM, Cortes JE (2009) Mechanisms of primary and secondary resistance to imatinib in chronic myeloid leukemia. Cancer Control 16(2):122-131

25. Volpe G, Panuzzo C, Ulisciani S, Cilloni D (2009) Imatinib resistance in CML. Cancer Lett 274(1):1-9

26. Garg RJ, Kantarjian H, O'Brien S, Quintas-Cardama A, Faderl S, Estrov $\mathrm{Z}$ et al (2009) The use of nilotinib or dasatinib after failure to 2 prior tyrosine kinase inhibitors: long-term follow-up. Blood 114(20):4361-4368

27. Quintas-Cardama A, Cortes J (2009) Chronic myeloid leukemia in the tyrosine kinase inhibitor era: what is the best therapy? Curr Oncol Rep 11(5):337-345 
28. Jabbour E, Cortes J, Kantarjian H (2009) Treatment selection after imatinib resistance in chronic myeloid leukemia. Target Oncol 4 (1):3-10

29. Peng B, Lloyd P, Schran H (2005) Clinical pharmacokinetics of imatinib. Clin Pharmacokinet 44(9):879-894

30. Gardner ER, Burger H, van Schaik RH, van Oosterom AT, de Bruijn EA, Guetens G et al (2006) Association of enzyme and transporter genotypes with the pharmacokinetics of imatinib. Clin Pharmacol Ther 80(2):192-201

31. Li-Wan-Po A, Farndon P, Cooley C, Lithgow J (2010) When is a genetic test suitable for prime time? predicting the risk of prostate cancer as a case-example. Public Health Genomics 13:55-62. doi: $10.1159 / 000218710$

32. Li-Wan-Po A (2010) Pharmacogenetics of CYP2C19: functional and clinical implications of a new variant CYP2C19*17. Br J Clin Pharmacol. doi:10.1111/j.1365-2125.2009.03578.x

33. Meyer zu Schwabedissen HE, Kim RB (2009) Hepatic OATP1B transporters and nuclear receptors PXR and CAR: interplay, regulation of drug disposition genes, and single nucleotide polymorphisms. Mol Pharm 6(6):1644-1661

34. Willson TM, Kliewer SA (2002) PXR, CAR and drug metabolism. Nat Rev Drug Discov 1(4):259-266

35. Burk O, Wojnowski L (2004) Cytochrome P450 3A and their regulation. Naunyn Schmiedebergs Arch Pharmacol 369(1):105124

36. Takagi S, Nakajima M, Mohri T, Yokoi T (2008) Posttranscriptional regulation of human pregnane $\mathrm{X}$ receptor by micro-RNA affects the expression of cytochrome P450 3A4. J Biol Chem 283(15):9674-9680
37. Mishra PJ, Merlino G (2009) MicroRNA reexpression as differentiation therapy in cancer. J Clin Invest 119(8):2119-2123

38. Benet LZ (2009) The drug transporter-metabolism alliance: uncovering and defining the interplay. Mol Pharm 6(6):1631-1643

39. Gurney H, Wong M, Balleine RL, Rivory LP, McLachlan AJ, Hoskins JM et al (2007) Imatinib disposition and ABCB1 (MDR1, P-glycoprotein) genotype. Clin Pharmacol Ther 82(1):33-40

40. Petain A, Kattygnarath D, Azard J, Chatelut E, Delbaldo C, Geoerger B et al (2008) Population pharmacokinetics and pharmacogenetics of imatinib in children and adults. Clin Cancer Res 14(21):7102-7109

41. Dressman MA, Malinowski R, McLean LA, Gathmann I, Capdeville R, Hensley M et al (2004) Correlation of major cytogenetic response with a pharmacogenetic marker in chronic myeloid leukemia patients treated with imatinib (STI571). Clin Cancer Res 10(7):2265-2271

42. McLean LA, Gathmann I, Capdeville R, Polymeropoulos MH, Dressman M (2004) Pharmacogenomic analysis of cytogenetic response in chronic myeloid leukemia patients treated with imatinib. Clin Cancer Res 10(1 Pt 1):155-165

43. Bolton AE, Peng B, Hubert M, Krebs-Brown A, Capdeville R, Keller U et al (2004) Effect of rifampicin on the pharmacokinetics of imatinib mesylate (Gleevec, STI571) in healthy subjects. Cancer Chemother Pharmacol 53(2):102-106

44. O'Brien SG, Meinhardt P, Bond E, Beck J, Peng B, Dutreix C et al (2003) Effects of imatinib mesylate (STI571, Glivec) on the pharmacokinetics of simvastatin, a cytochrome p450 3A4 substrate, in patients with chronic myeloid leukaemia. Br J Cancer 89 (10): $1855-1859$ 